\title{
Planejamento integrado de recursos como estratégia de implantação da gestão hídrica
}

\section{no Brasil}

\author{
Integrated resource planning as a strategy for implementing water management in Brazil \\ La planificación integrada de recursos como estrategia para implementar la gestión del agua en \\ Brasil
}

Recebido: 19/04/2021 | Revisado: 26/04/2021 | Aceito: 29/04/2021 | Publicado: 30/04/2021

Fabricio Quadros Borges

ORCID: https://orcid.org/0000-0002-1326-959X

Universidade da Amazônia, Brasil posdoctorborges@gmail.com

\begin{abstract}
Resumo
Esta investigação possui o objetivo de analisar o planejamento integrado de recursos como estratégia de implantação da gestão hídrica no Brasil. A Agência Nacional de Águas e a Secretaria Nacional de Segurança Hídrica deram início no ano de 2019, a construção do novo Plano Nacional de Recursos Hídricos, onde constam estratégias para a articulação institucional do plano, que possui horizonte até o ano de 2040. É nesta perspectiva, que este artigo procura colaborar por meio da contribuição do planejamento integrado de recursos hídricos enquanto instrumento a favor da gestão hídrica brasileira. A metodologia deste estudo está apoiada em um levantamento bibliográfico e documental sobre as categorias Planejamento Integrado de Recursos e Gestão dos Recursos Hídricos no Brasil, de maneira a viabilizar reflexões sobre possibilidades de aperfeiçoamentos da gestão hídrica no país. O estudo constatou uma necessidade de promover um planejamento de ações integradas que estejam alicerçadas em um caráter estratégico, participativo e descentralizado na gestão hídrica; capazes de criar um ambiente que reforce o desenvolvimento de novos arranjos institucionais com potencial de absorção e implantação de seus demais pressupostos, destacando a relevância de um processo de tomada de decisão aberto e participativo, quanto à gestão dos recursos hídricos.
\end{abstract}

Palavras-chave: Planejamento; Recursos hídricos; Gestão hídrica.

\begin{abstract}
This investigation aims to analyze integrated resource planning as a strategy for implementing water management in Brazil. The National Water Agency and the National Water Security Secretariat began in 2019, the construction of the new National Water Resources Plan, which contains strategies for the institutional articulation of the plan, which has a horizon until the year 2040. It is in this perspective, that this article seeks to collaborate through the contribution of integrated water resources planning as an instrument in favor of Brazilian water management. The methodology of this study is supported by a bibliographic and documentary survey on the categories Integrated Planning of Resources and Management of Water Resources in Brazil, in order to enable reflections on possibilities for improvements in water management in the country. The study found a need to promote integrated action planning that is based on a strategic, participatory and decentralized character in water management; capable of creating an environment that reinforces the development of new institutional arrangements with the potential for absorption and implementation of its other assumptions, highlighting the relevance of an open and participatory decision-making process, regarding the management of water resources.
\end{abstract}

Keywords: Planning; Water resources; Water management.

\section{Resumen}

Esta investigación tiene como objetivo analizar la planificación integrada de recursos como estrategia para implementar la gestión del agua en Brasil. La Agencia Nacional del Agua y la Secretaría Nacional de Seguridad Hídrica iniciaron en 2019, la construcción del nuevo Plan Nacional de Recursos Hídricos, que contiene estrategias para la articulación institucional del plan, que tiene un horizonte hasta el año 2040. Es en esta perspectiva, que este artículo busca colaborar a través del aporte de la planificación integrada de los recursos hídricos como instrumento a favor de la gestión del agua brasileña. La metodología de este estudio se apoya en una encuesta bibliográfica y documental sobre las categorías Planificación Integrada de Recursos y Gestión de Recursos Hídricos en Brasil, con el fin de permitir reflexiones sobre las posibilidades de mejora en la gestión del agua en el país. El estudio encontró la necesidad de promover una planificación de acción integrada que se base en un carácter estratégico, participativo y descentralizado en la gestión del agua; capaz de generar un entorno que refuerce el desarrollo de nuevos arreglos institucionales con potencial de 
absorción e implementación de sus otros supuestos, resaltando la relevancia de un proceso de toma de decisiones abierto y participativo, en materia de gestión de los recursos hídricos.

Palabras clave: Planificación; Recursos hídricos; Administracion del Agua.

\section{Introdução}

A água compreendida como um bem fundamental para a vida humana e para o processo de desenvolvimento econômico, social e ambiental dos países, desperta inúmeros questionamentos sobre a sua utilização racional. É um recurso natural que possui vínculos enquanto elemento bioquímico de seres vivos, enquanto meio de sobrevivência de várias espécies, enquanto componente representativo de valores sociais e culturais. Acrescenta-se a estes vínculos, o elemento produtivo, por meio da confecção de mercadorias. A água se encontra no foco de disputa internacional do capitalismo e o seu território de atuação são as nações onde existem as principais reservas potáveis de água do planeta, com estruturas de produção e serviços públicos sendo operados de maneira estatal (Calisto, 2020). O crescimento populacional, a industrialização e a expansão da agricultura no Século XX agravou a escassez e a degradação dos recursos hídricos, e por esta razão, a gestão das águas passou a fazer parte dos debates políticos e socioeconômicos (Castro, 2012). O entendimento vigente é o de que a água compreende um recurso finito, escasso e valorizado economicamente; neste sentido, a necessidade deste recurso conduz fornecedores e usuários a negociarem no ambiente institucional atual. A escassez de água é indicada como um dos mais importantes motivos para a ocorrência de conflitos internacionais no futuro, sobretudo por forçar a emigração de populações das áreas que sofrem com a situação (Castro, 2012).

O documento de 1988, chamado Nosso Futuro Comum, afirma que por muitos anos a sociedade demonstrava preocupação a respeito o que poderia ocorrer a partir dos padrões vigentes de exploração de recursos naturais. De acordo com o documento, o foco está concentrado em duas questões. Na primeira, trata-se a maneira com que os prejuízos oriundos ao meio ambiente. Na segunda, abordam-se as competências dos países na intenção de promover a utilização sustentável de recursos hídricos (Silva, Herreros \& Borges, 2017). A gestão e conservação dos recursos hídricos constitui-se como deliberação de natureza política, promovida sobretudo pela escassez desses recursos, que impõe limites ao desenvolvimento socioeconômico e é condicionada às pressões de seus diversos usuários (Trindade \& Scheibe, 2014). De acordo com Trindade e Scheibe (2014), as políticas públicas no segmento hídrico precisam focar a proteção da coletividade e antecipar os riscos de contaminação e superexploração desses recursos, destacando que isso exige opções que vão desde a gestão de conflitos e posições contrárias de setores economicamente ativos e influentes no meio político até elementares decisões sobre definições vinculadas a esta temática.

No Brasil, em 2019, a Agência Nacional de Águas e a Secretaria Nacional de Segurança Hídrica deram início a um processo de elaboração de um novo Plano Nacional de Recursos Hídricos, onde se verificam estratégias para a articulação institucional do plano, que possui horizonte até o ano de 2040; o novo Plano Nacional de Recursos Hídricos será elaborado ao longo de 2021 conforme uma estratégia participativa dos diversos atores e interessados na agenda de recursos hídricos do país (Ana, 2021). Nesta perspectiva, esta investigação possui o objetivo de analisar o planejamento integrado de recursos como estratégia de implantação da gestão hídrica no Brasil. A intenção pé a de colaborar por meio da contribuição do planejamento integrado de recursos hídricos enquanto instrumento a favor do aperfeiçoamento da gestão hídrica brasileira.

A Constituição Federal de 1988 definiu a propriedade estatal das águas em seus artigos 20, III e 26, I, definindo uma esfera federal de liderança das águas; definiu ainda como competência de a União implantar sistema nacional de gerenciamento de recursos hídricos e definir critérios de outorga de direito de seu uso (Brasil, 1988). Esse último foi atendido por meio da promulgação da Lei 9.433, de 08 de janeiro de 1997, que estabelece a Política Nacional de Recursos Hídricos, inaugura o Sistema Nacional de Gerenciamento de Recursos Hídricos e regulamenta o inciso XIX do art. 21 da Constituição Federal; a legislação estabelece como instrumentos da Política Nacional de Recursos Hídricos: os Planos de Recursos Hídricos; o enquadramento dos 
corpos de água em classes, segundo os usos preponderantes da água; a outorga dos direitos de uso de recursos hídricos; a compensação a município; o Sistema de Informações sobre Recursos Hídricos (Brasil, 1997).

O novo Plano Nacional de Recursos Hídricos traz uma possibilidade de elaboração de um desenho estratégico que possa envolver os diversos atores e considerar as demandas nacionais para estes recursos. Neste sentido, este artigo se justifica pela possibilidade de agregar ao ambiente de gestão hídrica no país, a proposta do planejamento integrado de recursos, que representa uma ferramenta neste processo que leva em consideração opções de utilização de recursos do lado da oferta e da demanda, buscando um posicionamento de alinhamento com o desenvolvimento sustentável, de modo a considerar aspectos quantitativos e qualitativos.

\section{Referencial Teórico}

O planejamento integrado de recursos compreende é um processo de planejamento direcionado a otimização da disposição de recursos, que considera aspectos como o uso racional de insumos energéticos, a determinação da capacidade de conservação, custos e benefícios, entre outros aspectos. Esta seção desenvolve uma abordagem específica do Planejamento Integrado de Recursos (PIR) e para este desafio foi dividida em quatro partes: abordagem do PIR e desenvolvimento sustentável; fundamentos do PIR; e estrutura do PIR.

\subsection{Abordagem do Planejamento Integrado de Recursos e Desenvolvimento sustentável}

A abordagem do Planejamento Integrado de Recursos (PIR) consolidou-se em princípio nos Estados Unidos no final da década de 1980 e açambarcou a diversidade de processos empregados pelas concessionárias do setor elétrico daquele país para lidar com as abruptas mudanças estruturais germinadas em meados da década de 1970, quando se encerrou uma estável fase de declínio das tarifas de energia elétrica e seguiu-se para uma era de crescentes custos de capital e de insumos até a sua estabilização (Hirst, 2003; Baitelo 2011). Tal época foi marcante para a mudança paradigmática do planejamento dos recursos energéticos, além de registrar um panorama dramático especialmente para os países em desenvolvimento no que concerne ao encarecimento do principal insumo de energia: o petróleo, e à sua influência no aumento dos juros das dívidas externas. Também ganhou força, em paralelo, o movimento centrando nas discussões a respeito da questão ambiental, ressaltando os impactos negativos e ameaças provocadas pelo uso desordenado da energia e de seu consumo de recursos não renováveis, como os combustíveis fósseis. Eis que o emprego potencializado dos recursos energéticos e a questão ambiental assumem a condição de componentes essenciais do planejamento integrado de recursos energéticos (Jannuzzi \& Swisher, 1997; Baitelo 2011; Leite \& Bajay, 2004).

O Planejamento Integrado de Recursos pode ser compreendido na condição de ferramenta no processo de planejamento que considera alternativas de uso de recursos do lado da oferta e da demanda, em bases qualitativas e quantitativas, objetivando bases comprometidas com o referencial normativo do desenvolvimento sustentável (Uadeta et al., 2004; Manca, 2008).

O planejamento integrado de recursos (PIR) para o setor elétrico, notadamente, é uma evolução do planejamento energético tradicionalmente fundamentado no paradigma do custo mínimo como premissa para a expansão da oferta de energia. Sua adoção viabiliza a formação de um sistema mais benéfico entre os diversos objetivos adjacentes ao desenvolvimento do setor elétrico, uma vez que amplia a gama de fatores importantes, como a gestão pela eficiência energética do lado da demanda e eliminação ou redução dos impactos ambientais provocados pelas tecnologias utilizadas na esfera da produção (Jannuzzi e Swisher, 1997; Reis, Fadigas \& Carvalho, 2012). Sob esse prisma, a consistência do PIR reside no desenvolvimento e na aplicação conjunta de métodos em multicritérios para análise e projeções em diferentes sentidos (modelos de análise top down ou bottom up), enfoques (produção ou consumo) e subsetores (residências, indústrias, agronegócios, etc.), ao passo que a consideração do critério ambiental em tais modelos - seja por meio de regulação, concessão de incentivos fiscais e subsídios, ou internalização dos custos socioambientais - viabiliza uma tendência de substituição por tecnologias de geração de energia 
renovável relegando ao crescente desuso a prática exploratória de recursos não renováveis (Cormio et al., 2003; Kaya \& Kahraman, 2010). Outrossim, é importante considerar o contexto institucional em que foi concebido o PIR para o setor elétrico nos EUA, no qual se adota o princípio da organização como estrutura social capaz de reunir as competências técnicas fundamentais para o desenvolvimento da atividade de planejamento, reforçando a visão de que a busca pelo aperfeiçoamento da técnica pode requerer a concentração de capitais e recursos para a obtenção de benefícios com a inovação e a economia de escala. Contudo, Hirst (2003) indica a participação pública como aspecto essencial no processo de definição do mix de recursos energéticos a ser consumida dada a variedade de atores que representam diferentes interesses afetados pelas ações resultantes dos planos das empresas especializadas do setor.

O PIR foi apresentado ao contexto brasileiro na segunda metade da década de 1990 por meio de iniciativas oriundas de instituições de ensino superior e de institutos de pesquisas, dos quais se destacam os trabalhos produzidos pelo Grupo de Energia do Departamento de Engenharia de Energia e Automação Elétrica da Escola Politécnica da Universidade de São Paulo (GEPEA) e pelo Planejamento de Sistemas Energéticos (PSE) da Faculdade de Engenharia Mecânica na Universidade Estadual de Campinas. Sua primeira aplicação ocorreu na região do Médio Paranapanema no Estado de São Paulo (Uadeta et al., 2004), ao passo que seus experimentos mais recentes foram realizados no município de Araçatuba (Cicone Junior et al., 2008). No âmbito das concessionárias, somente a Companhia Elétrica de Minas Gerais (CEMIG) adotou uma proposta de planejamento baseada no PIR, embora esta não tenha sido colocada em pratica ou tornada publicamente disponível (Baitelo, 2011).

De acordo com Souza e Santos (2006), ao refletirem sobre a questão da participação publica circunscrita em um contexto regional da Amazônia, a viabilidade do PIR é sujeita a disposição política para que se estabeleça um modelo institucional adequado ao método de planejamento, com a descentralização das decisões tomadas pelos agentes de âmbito federal para os representantes dos estados e municípios. Assumiria o PIR, portanto, a roupagem de um método de aplicação de políticas públicas específicas para e setor elétrico, e sob esse modo de interpretação é retomada a discussão em torno do modelo institucional mais adequado a essa abordagem de planejamento e gestão dos recursos energéticos. Diante da coligação do que foi até aqui discutido, pode-se afirmar que o PIR busca o desenvolvimento de ações que obtenham a máxima eficiência energética atendendo ao requisito de sustentabilidade, pressupondo o envolvimento de todos os grupos de interesse em sua formulação. Tal assertiva também se adequa aos atributos chaves elencadas por Hirst (2003) a respeito dessa abordagem, a saber: observação da ampla variedade de opções de oferta e demanda; consideração de custos ambientais e sociais nos serviços de provimento e consumo de energia; participação pública no processo de desenvolvimento do plano e análise de incerteza sobre fatores externos e opções de recursos. Assim, análise da consistência do PIR associada aos seus pressupostos em uma dada realidade é aqui proposta em três dimensões ou aspectos interdependentes em relações que exprimam convergência: técnica, socioambiental e institucional.

O exame da literatura do PIR sobre seus aspectos conceitual, estrutural e de seu contexto histórico proporciona a mostra de que o seu desenvolvimento não deriva somente do pragmatismo baseado no aperfeiçoamento tecnológico e econômico das diversas formas de uso mais eficiente da eletricidade, pois se trata também da incorporação de fenômenos de ordem social pelos quais os valores que expressam o paradigma da sustentabilidade foram agregados ao planejamento do setor elétrico. Desse modo, a essência do PIR permanece atual desde o seu surgimento da década de 1980, uma vez que representa o referencial normativo do desenvolvimento sustentável para o planejamento de setores econômicos cujas atividades que requeiram o constante emprego de recursos naturais. A sustentabilidade é mantida por um tripé composto pelo fator social, econômico e ambiental. Esses três fatores que dão a essência para qualquer plano de desenvolvimento sustentável e sem um deles não é possível falar em sustentabilidade (Ferreira, 2020).

Nesta perspectiva, esta discussão conceitual está apoiada nos estudos de Godard (2002) sobre o desenvolvimento durável. Conforme Godard (2002), os atributos mais relevantes do desenvolvimento durável são descritos da seguinte maneira: 
transforma em utopia positiva o negativismo; detém aspectos éticos; atenção com as gerações futuras; e levanta condições de exame da revisão dos conteúdos socioeconômicos junto ao debate do desenvolvimento.

\subsection{Fundamentos do Planejamento Integrado de Recursos}

Como processo de planejamento, o PIR é orientado para a busca da melhor distribuição dos recursos disponíveis por meio do emprego racional e utilização das formas de conservação destes sob a perspectiva de seus usos finais. Seguindo esse sentido, toma-se diretrizes de apoio essenciais ao PIR, a ampliação da abrangência dos recursos a serem utilizados, com prioridade para as fontes renováveis e limpas em suas relações de combinação com os demais aspectos de uma produção sustentável; bem como a inclusão de diversos atores representantes de interesses não somente ligados às empresas do setor elétrico, mas também de usuários de outros setores da economia e da comunidade em geral (Uadeta et al., 2004). Tais diretrizes assentam ao PIR uma visão holística para o tratamento dos recursos ao abordar a questão da energia sobre diversas perspectivas, seja como uma mercadoria (commodity), uma necessidade social, um recurso estratégico ou ecológico (Jannuzzi \& Swisher, 1997), pesando junto aos aspectos técnicos e econômicos, os aspectos sociais e ambientais. Desta feita, além do aspecto econômico pautado no menor custo, são agregados ao PIR atributos qualitativos (ambientais, sociais e políticos) que extrapolam o escopo do ferramental centrado somente na redução dos custos de instalação, manutenção e operação típico do paradigma tradicional de planejamento do setor elétrico (Cicone Júnior et al., 2008), requerendo o emprego de técnicas que possibilitem a internalização de custos sociais, institucionais e ambientais, a exemplo do Método de Valoração Contingente (Furtado, 2013) ou da Contabilidade de Custo Total (Cicone Júnior et al., 2008). Uma vez internalizados esses atributos qualitativos na estimativa dos custos devidos a cada tipo de recurso, a definição do portfólio de recursos energéticos mais adequados para os diferentes cenários - projetados considerando os prováveis modos de uso final - é dotada de maior capacidade de ajuste entre os prazos curto, médio e longo. Além disso, a assunção de uma realidade complexa, que transcende os encadeamentos sistêmicos do setor elétrico, atribui ao PIR uma flexibilidade que permite lidar tanto com as probabilidades pouco controláveis, como sobre as incertezas absolutamente imprevisíveis, por meio de ajustes que levam em conta o dinamismo e a variabilidade dos fatores capazes de influenciar na definição do melhor portfólio de recursos, selecionado com base em técnicas elaboradas para processos de tomada de decisão, a exemplo do emprego da abordagem de Processo Hierárquico Analítico (PHA) adaptada por Cicone Junior el al. (2008).

Diante desta ampliação do espectro de fatores e possibilidades de utilização de recursos, o PIR naturalmente reforça o desenvolvimento de novos arranjos institucionais capazes de absorver e implantar seus demais pressupostos, enfatizando a importância de um processo decisório aberto e participativo, sobretudo competente para construir visões consuetudinárias ou resoluções alternativas para os interesses conflitantes provindo de diversos agentes, requerendo, para tanto, habilidades de coordenação (Beecher, 1995). Vale observar que as disposições de novos arranjos não prescindem do desenvolvimento ou utilização de mecanismos de mercado, a exemplo dos leilões e do varejo, pois a as metas de custo mínimo permanecem necessárias (Beecher, 1995). De fato, considerando as origens práticas do PIR para o setor elétrico, quando se observa as novas propostas de arranjos institucionais lançadas na virada do século XX para o século XXI, o denominador comum tem sido a mudança de foco de atuação do poder público, que deixa de ser investidor da indústria de eletricidade, passando a atuar, fundamentalmente, como regulador dos serviços públicos de energia (Uadeta et al., 2004).

\subsection{Estrutura do Planejamento Integrado de Recursos}

Destaca-se que antes de ser implantada no Brasil, ou mesmo estruturada pelas Nações Unidas, a necessidade de uma estrutura de gestão dos recursos hídricos já era verificada em algumas nações desenvolvidos, apesar de não haver unanimidade quanto ao modelo de gestão (Silva, Herreros \& Borges, 2017). No continente europeu, as associações de bacia da Alemanha 
foram criadas nos primeiros anos do Século XX; na França, a Companhia Nacional do Rhone, fundada em 1933, voltada ao gerenciamento da navegação, editou em 1964 a Lei das Águas; na Inglaterra e País de Gales, a gestão integrada começou a ser desenvolvida em 1974 e; nos Estados Unidos da América começaram a sua gestão integrada de recursos hídricos em 1933, com a inauguração da Tennessee Valley Authority (Silva \& Pruski, 2000). Inúmeros países latino-americanos, nos anos de 1960, demonstraram interesse pelo modelo dos Estados Unidos da América, e o Brasil não foi exceção.

O Brasil, conforme Silva e Pruski (2000), adotou o modelo, especialmente na Companhia de Desenvolvimento do Vale são Francisco (Codevasf). Todavia, este modelo se mostrou impróprio às nações em desenvolvimento, com ampla diversidade de interesses e heterogeneidades regionais (Silva, Herreros \& Borges, 2017). Já o modelo elaborado na França, era adepto de características como: "coordenação administrativa; planificação por bacias como unidades administrativas (incluindo uso do solo); participação dos usuários (comitês); contribuição por uso da água; e agências de bacias" (Silva \& Pruski, 2000). Conforme Tortajada (2016), este caminho francês, que se apresenta como uma das grandes influências do modelo de GIRH, chamou a atenção da política do Brasil e, conforme Braga (2008), ao ser implantado no país, transformou-se em uma das estruturas de gestão mais modernas para os recursos hídricos, na América Latina.

A constituição do PIR, por sua concepção estar condicionada a existência de um processo, pode ser expressa mediante uma série de etapas, cujas relações pressupõem um encadeamento lógico que pode variar sutilmente de acordo com sua forma explicitada na literatura (Beecher, 1995; Reis, Fadigas \& Carvalho, 2012; D’Sa, 2005), assim como também por adequação à complexidade do objeto definido, à abrangência espacial e aos prazos de sua elaboração e aplicação. Não obstante a essas alterações, a estrutura do PIR remete a um cerne ordenado pelos itens, a saber: a) Objetivos e escopo do plano: os objetivos, bem como suas materializações por meio de metas, são definidos de maneira que contemplem os diversos interesses dos respectivos stakeholders envolvidos. Assim, por exemplo, a meta de prover acesso à energia elétrica em $100 \%$ dos domicílios de uma determinada região, deve incrementar a qualidade de vida das famílias de um modo confiável e seguro, viabilizando o retorno dos investimentos necessários ao mesmo tempo em que a manutenção de custos e taxas razoáveis seja garantida, a partir de técnicas e ações que reduzam ao mínimo possível, caso não anulem, os impactos ambientais e sociais (D’Sa, 2005). Igualmente necessária como as metas aos objetivos, é a delimitação do escopo ao plano, para que sejam identificados os limites de sua cobertura no tempo e no espaço, demando um conhecimento prévio do contexto histórico, geográfico e institucional do objeto delimitado (Beecher, 1995); b) Projeções e estimativas: nesta etapa são elaborados e apresentados os diferentes cenários resultantes das diversas possibilidades identificadas por combinações e mudanças entre os fatores capazes de influenciar a variação de demanda futura e suas respectivas implicações ambientais, sociais e econômicas. É condição necessária para a realização desse estágio, portanto, a identificação das variáveis portadoras de influências e a realização de coleta de dados para o estabelecimento de um ano base de projeção. Também é necessária a identificação e valoração dos recursos tanto de oferta como de demanda sob uma abordagem multicritérios, de modo que os custos estimados para um projeto não reflitam somente os seus aspectos técnicos e econômicos (Reis, Fadigas \& Carvalho, 2012); c) Tomada de decisões e estratégias: tendo por base as projeções de demandas correspondentes a cada um dos cenários futuros vislumbrados, são desenvolvidos para o mesmo período os mix alternativos de recursos de oferta e demanda, integrados com seus custos, de maneira a considerar os custos socioambientais, bem como seus graus de eficiência diante de cada cenário estabelecido. A comparação entre os mix de recursos desenvolvidos para atributos semelhantes pode então ser realizada sob o critério de seus custos, estipulando-se um ranking no qual o mix que demonstrar o menor custo, sob o ponto de vista de todas as partes interessadas envolvidas, será o mais adequado para a seleção. Dito isto, sem ignorar os riscos e incertezas atinentes à decisão tomada, os agentes planejadores poderão formular as melhores políticas e estratégias de execução do plano (D’Sa, 2005). d) Ações de implantação: a obtenção dos recursos selecionados requer o estabelecimento de um plano de ações no qual esteja contido um cronograma de execução focado no curto prazo, e que demonstre coordenação entre os todos os passos e metas estipuladas. Também deve estar contido o mecanismo de 
flexibilidade do plano em face de possíveis mudanças das condições de demanda, assim como os critérios a serem monitorados para avaliar os efeitos esperados no decorrer da execução (Beecher, 1995; Reis, Fadigas \& Carvalho, 2012). e) Revisão e avaliação: considerando o prazo definido para o cronograma do plano de ação, é importante que nele seja definido um período a ser revisado e comunicado por meio de relatórios aos stakeholders e a sociedade de um modo geral, viabilizando uma avaliação transcendente aos critérios do plano.

A realização de cada etapa do processo de planejamento, por este ser fundamentado no PIR, pressupõe o envolvimento de representantes dos diversos e, em alguns casos, contraditórios interesses das partes envolvidas, dispondo para isso vários métodos de condução da participação pública (Beecher, 1995). Diante dessa diversidade e interdependência de interesses, fazse necessário o desenho de uma estrutura de coordenação na qual algumas lideranças sejam destacadas para a condução do processo de planejamento ou de algumas suas etapas. Tal necessidade enseja o questionamento acerca de quem lidera o processo do planejamento. A resposta é dependente das estruturas organizacional e institucional, existentes ou a serem concebidas para a utilização dos recursos demandados. Destaca-se que a associação dos planos de recursos hídricos ao PIR requer um processo efetivo de gestão participativa dos recursos. Este modelo de planejamento integrado deve atender aos propósitos oriundos de um processo que determine o que é efetivamente relevante à comunidade (Souza, 2003).

\section{Metodologia}

A investigação, conforme a classificação de Vergara (2009) quanto à abordagem do problema, caracteriza-se como pesquisa qualitativa e quanto ao seu gênero como estudo teórico. É qualitativa, pois busca proporcionar uma melhor visão e entendimento sobre a relação das categorias Planejamento integrado de recursos e a Gestão de recursos hídricos. É teórico na medida em que propõe uma revisão da discussão de autores que interpretam a relação entre estas categorias conceituais. Este tipo de pesquisa é dirigido no intuito de reconstruir teorias, quadros de referência, condições que explicam a realidade e discussões pertinentes. A metodologia deste estudo está apoiada em um levantamento bibliográfico e documental sobre as categorias Planejamento Integrado de Recursos e Gestão dos Recursos Hídricos no Brasil, de maneira a viabilizar reflexões sobre possibilidades de aperfeiçoamentos da gestão hídrica no país. O local de estudo desta investigação é o Brasil. O Brasil constituise como uma das nações mais bem servidas de recursos hídricos do mundo, possuindo $12 \%$ do total do planeta. Mas a distribuição destes recursos no país ocorre de forma desigual pelo território e ainda há muito desperdício na sua utilização. A distribuição regional dos recursos hídricos é de 70\% para a região Norte, $15 \%$ para a Centro-Oeste, $12 \%$ para as regiões Sul e Sudeste, que revelam o maior consumo de água, e 3\% para a Nordeste (Castro, 2012).

\section{Resultados e Discussão}

Esta seção desenvolve um esforço teórico de análise do planejamento integrado de recursos como estratégia de implantação da gestão hídrica no Brasil. Este esforço surge diante da postura da Agência Nacional de Águas e da Secretaria Nacional de Segurança Hídrica de darem início no ano de 2019, a um processo de construção do novo Plano Nacional de Recursos Hídricos, onde constam estratégias para a articulação institucional do plano, que possui horizonte até o ano de 2040.

A gestão integrada de recursos hídricos compreende um conjunto de etapas que favorece o monitoramento do desenvolvimento e gestão de águas e recursos vinculados como terra; o objetivo é o monitoramento de modo otimizado, para a promoção de bem-estar social, igualdade, viável economicamente, e com preocupação sustentável com os ecossistemas. As diretrizes responsáveis pela estrutura da Gestão Integrada dos Recursos Hídricos são: definição da água como um recurso finito e vulnerável; definição de que o desenvolvimento e a gestão integrada dos recursos hídricos precisam estar inseridos em uma percepção de participação entre os envolvidos.; definição de que as mulheres executam uma missão fundamental na 
administração e proteção do recursos água; e reconhecimento de que a água possui valor econômico nas suas utilizações (ICWE, 1992).

Na prática, este tipo de gestão compreende uma dinâmica de implantação da supervisão de águas, de modo otimizado. Esta supervisão ocorre tomando como foco o bem-estar social. Neste processo, são formuladas diretrizes, normativas e políticas com potencial de elaboração de mecanismos de orientação de tomada de decisão, a luz dos recursos disponíveis. Naturalmente, neste panorama são elaboradas normas, políticas, análises socioeconômicas e é justamente aí, que entra a contribuição do PIR. O PIR fortalece o desenvolvimento de novos arranjos institucionais com potencial de absorção e implantação de mecanismos que destaquem a relevância de um processo de tomada de decisão aberto e participativo.

Neste âmbito de entendimento, esta discussão conceitual está apoiada nos estudos de Godard (2002) sobre o desenvolvimento durável. De acordo com Godard (2002), os atributos principais do desenvolvimento durável podem ser assim expressos: transforma em utopia positiva o que é visto de modo negativo (a poluição, a degradação); manifesta um conteúdo ético: a preocupação com todas as gerações humanas; apazigua preocupações com relação ao futuro; abriga apropriações diversificadas, dada sua flexibilidade; e abre a possibilidade de revisão dos conteúdos econômicos e sociais na problemática do desenvolvimento. A gestão integrada de recursos naturais deve estar, portanto, imbuída de uma visão estratégica do desenvolvimento no longo prazo, que lhe confere um sentido mais além dos usos cotidianos. Nesta lógica, as bases da Gestão Integrada de Recursos possuem como princípio teórico Godard (2002).

A gestão dos recursos hídricos no Brasil não incorpora adequadamente os princípios do PIR. Esta constatação se dá em virtude da identificação de que as ações de caráter estratégico não se encontram apoiadas em um ambiente participativo e descentralizado na gestão hídrica. Os arranjos institucionais revelam fragilidade pelo viés decisório. As dificuldades de harmonia entre as esferas governamentais, a ausência de uma lógica territorial de gestão, a ausência de apoio aos comitês de bacias, as lacunas na legislação e as falhas nas avaliações técnico-científicas colaboram para a compreensão deste quadro que afasta a gestão hídrica no país dos princípios do PIR.

A totalidade destes percalços, como bem observa a literatura, estabelece um significativo desafio à gestão integrada dos recursos hídricos no Brasil, notadamente frente das diversidades política, econômica, social e ambiental das regiões brasileiras que se refletem nos ritmos de regulamentação e implementação dos sistemas estaduais de gestão dos recursos hídricos, severamente dispares entre os estados brasileiros. Na perspectiva de possibilidades de aplicação da metodologia do Planejamento Integrado de Recursos como estratégia de integração na gestão dos recursos hídricos brasileiros, destaca-se que a estrutura do Planejamento Integrado de Recursos recomenda os itens: objetivos e escopo do plano; Projeções e estimativas; tomada de decisões e estratégias; ações de implantação; e revisão e avaliação.

A aplicação do PIR na sugestão por bacias hidrográficas possibilita exames de riscos e incertezas, assim como, considera, nos estudos de inventário e de viabilidade dos empreendimentos os planos de recursos hídricos das bacias em que estarão localizadas as usinas e não somente os empreendimentos em questão. As conexões entre o Planejamento integrado de recursos e a gestão de recursos hídricos sugere uma construção de um processo participativo de gestão. Em um planejamento integrado procura-se atender as demandas das comunidades envolvidas. Neste sentido, uma aproximação do PIR à gestão de recursos hídricos passa por estudos preliminares que possam alicerçar o planejamento junto as bacias hidrográficas. Logo, etapas como de estudos hidrológicos, de viabilidade, necessidade de projetos básicos e aplicação de mecanismos de medidas mitigadoras de impactos socioambientais, devem ser observadas criteriosamente.

Elucida-se que a análise teórica do Planejamento Integrado de Recursos demonstra interfaces no campo conceitual com a análise do desenvolvimento sustentável. As interfaces surgem no instante em que o Planejamento Integrado de Recursos favorece opções de utilização de recursos em bases que atendam a contento as dimensões socioeconômica e ambiental do desenvolvimento sustentável, quantitativa e qualitativamente. A propriedade da abordar integradamente os recursos reside na 
busca de estratégias que contemplem condições de uso destes recursos de maneira a não superar a sua capacidade de recuperação. Neste sentido, o planejamento integrado de recursos ocupa-se não apenas de preocupações com as gerações presentes, mas também com as gerações futuras.

As conexões entre o PIR e a gestão de recursos hídricos revela uma extensão de planos que envolvem, além dos recursos hídricos, mas também recursos energéticos. O PIR recomenda à Gestão de recursos hídricos uma distribuição mais estratégica dos recursos disponíveis por meio do emprego racional e utilização das formas de conservação destes sob a perspectiva de seus usos finais e o ambiente energético é perfeitamente contemplado neste processo de planejamento. Nesta lógica, adotam-se focos de apoio fundamentais ao PIR, a ampliação da abrangência dos recursos a serem utilizados, com prioridade para as fontes renováveis e limpas de geração de energia e suas relações de combinação com os demais aspectos de uma produção sustentável.

Em suma, a investigação inferi que o ambiente de gestão pública não detém fundamentos relevantes do Planejamento Integrado de Recursos. Verificou-se uma necessidade de fortalecer condutas que estejam alinhadas estrategicamente ao ambiente de participação e descentralização na gestão dos recursos hídricos; um ambiente que beneficie o desenvolvimento de novos arranjos institucionais.

\section{Conclusão}

Esta investigação indagou de que maneira o planejamento integrado de recursos poderia contribuir como estratégia de implantação da gestão hídrica no Brasil. Assim, o desafio deste foi o de exame das possibilidades de aplicação da metodologia do Planejamento Integrado de Recursos como estratégia de integração na gestão dos recursos hídricos brasileiros. Este esforço partiu da hipótese da necessidade de levantamento de subsídios ao processo decisório na gestão pública de águas no Brasil. Observou-se que é plausível a constatação dos avanços brasileiros no que se refere ao uso responsável dos recursos hídricos diante dos riscos de escassez, assim como a crescente adequação ao modelo de Gestão Integrada dos recursos hídricos, modelo que se tornou um marco para gestão no Brasil e no mundo, permitindo predições favoráveis às futuras gerações.

O estudo indica que o ambiente de gestão pública carece de absorção de princípios importantes do Planejamento Integrado de Recursos. Constatou-se ainda a necessidade de promover ações que estejam alicerçadas em um caráter estratégico, participativo e descentralizado na gestão hídrica; um ambiente que reforce o desenvolvimento de novos arranjos institucionais capazes de absorver e implantar seus demais pressupostos, destacando a relevância de um processo de tomada de decisão aberto e participativo.

$\mathrm{O}$ ambiente das futuras investigações, deveria estar associado a operacionalização prática dos princípios do Planejamento Integrado de Recursos junto ao ambiente de gestão integrada de recursos hídricos no Brasil, de modo a contemplar as suas diretrizes e usufruir de seus princípios estratégicos. A criação e análise de mecanismos capazes de operacionalizar, isto é, colocar em prática as bases do PIR poderiam favorecer o levantamento de subsídios decisivos para orientação das políticas públicas por meio da orientação do processo decisório.

\section{Referências}

Agência Nacional de Águas [ANA]. (2021). O novo plano nacional de recursos hídricos (2022-2040). http://conjuntura.ana.gov.br/pnrh

Baitelo, R. L. (2011). Modelo de cômputo e valoração de potenciais completos de recursos energéticos para o planejamento integrado de recursos. (Tese de Doutorado). Escola Politécnica, Universidade de São Paulo, São Paulo.

Beecher, J. A. (1995). Integrated resource planning fundamentals. Journal of the American Water Works Association. 87(6).

Brasil. (1988). Constituição da República Federativa do Brasil. http://www.planalto.gov.br/ccivil_03/constituicao/constituicaocompilado.htm.

Brasil. (1997). Lei 9.433, de 8 de janeiro de 1997. Política Nacional de Recursos Hídricos. Disponível em: http://www.planalto.gov.br/ccivil_03/leis/L9433.htm. 
Calisto, D. (2020). Brasil de Fato. https://www.brasildefato.com.br/2020/09/03/artigo-brasil-a-privatizacao-da-agua-faz-mal-ao-pais

Castro, C. N. de. (2012). Gestão das águas: experiências internacional e brasileira. Textos para discussão 1744. IPEA.

Cicone Jr., D., Udaeta, M. E. M., Grimoni, J. A. B. \& Galvão, L. C. R. (2008). Functionality of the Approach of Hierarchical Analysis In The Full Cost Accounting In The Irp Of A Metropolitan Airport. Energy Policy, 36, 991-998.

Cormio, C., Dicorato, M., Minoia, A. \& Trovato, M. (2003). A regional energy planning methodology including renewable energy sources and environmental constraints. Renewable and Sustainable. Energy Reviews, 7(2), 99-130.

Ferreira, R. de S. (2020). A importância do direito ambiental para o desenvolvimento sustentável e a preservação do meio ambiente. Research, Society and Development, $9(7)$.

Furtado, R. C. (2013). Custos ambientais da produção de energia elétrica. Synergia.

Gorard, O. (2002). A gestão integrada dos recursos naturais e o meio ambiente: conceitos, instituições e desafios de legitimação. In: Vieira, P. F. E Weber, J. (Org.) Gestão de recursos naturais renováveis e desenvolvimento: novos desafios para a pesquisa ambiental. Cortez.

Hirst, E. (2003). A good integrated resource plan: guidelines for electric utilities and regulators. Oak Ridge National Lab.

International Conference on Water and The Environment [ICWE]. (1992). The Dublin Statement on Water and Sustainable Development. Dublin, Ireland, on jan. 26-31.

Jannuzzi, G. de M. \& Swisher, J. N. P. (1997). Planejamento integrado de Recursos Energéticos. Autores Associados.

Kaya, T. \& Kahraman, C. (2010). Multicriteria renewable energy planning using an integrated fuzzy Vikor \& Ahp methodology: The case of Istanbul. Energy. $35(6), 2517-2527$

Leite, A. A. F., \& Bajay, S. V. (2004). Programas de eficiência energética no âmbito do planejamento integrado de recursos, aplicado a bacias hidrográficas. In: Congresso Brasileiro de Planejamento Energético, 4. Itajubá, MG, 2004. Anais, SBPE e UNIFEI, 11 p.

Manca, R. da S. (2008). O Planejamento integrado de recursos do setor energético como base para o gerenciamento dos recursos hídricos: aplicabilidade para o setor de abastecimento público de água em áreas urbanas. 2008. 99 f. (Dissertação de Mestrado). Pós-Graduação em Engenharia Mecânica e Planejamento de Sistemas Energéticos, FEM, Unicamp, Campinas, SP.

Pereira, D. S. P. \& Johnson, R. M. F. (2004). Descentralização da gestão dos recursos hídricos em bacias nacionais no Brasil. Revista de Gestão da Água, 2(1).

Reis, L. B. dos, Fadigas, E. A. F. A. \& Carvalho, C. E. (2012). Energia, recursos naturais e a prática do desenvolvimento sustentável. CEP, $6460,120$.

Silva, M. B, Herreros, M. M. A. G. \& Borges, F. Q. (2017). Gestão integrada dos recursos hídricos como política de gerenciamento das águas no Brasil. Rev. Adm. UFSM, 10(1), 101-115.

Silva, D. D. \& Pruski, F. F. (2000). Gestão de Recursos Hídricos: aspectos legais, econômicos, administrativos e sociais. Secretaria de Recursos Hídricos.

Souza, R. C. \& Santos, E. C. S. dos. (2006). Estado e desenvolvimento regional: a falta de compromisso com o setor elétrico da Amazônia, In: Scherer, Elenise, De Oliveira, José Aldemir (Org.). Amazônia: políticas públicas e diversidade cultural. Garamond.

Souza, R. S. F.de. (2003). Planejamento Integrado de Recursos no fornecimento de água tratada para o sistema de abastecimento da região metropolitana de Fortaleza: proposta de metodologia. (Tese de Doutorado). Florianópolis: UFSC, 221p.

Trindade, L. L. \& Scheibe, L. F. (2014). A gestão dos recursos hídricos a partir de uma análise das políticas públicas. Revista Brasileira de Políticas Públicas. Brasília, 4(2).

Tortajada, C. (2016). Institutions for Integrated river Basin Management in Latin America. Third World Center for Water Management.

Uadeta, M. E. M., Galvão, L. C. R., Gimenes, A. L. V. \& Fujii, R. J. (2004). Elementos de planejamento integrado de recursos energéticos. In: Congresso Brasileiro de Energia, 10, 2004, Anais. COPPE/UFRJ.

Vergara, S. C. (2009). Projetos e Relatórios de Pesquisa em Administração. Atlas. 